\title{
HETEROGENEITY OF SERBIAN CONSUMERS' PREFERENCES FOR LOCAL WINES: DISCRETE CHOICE ANALYSIS
}

\author{
Marija Kuzmanovićl, Dragana Makajić-Nikolić2 \\ *Corresponding authorE-mail: marija.kuzmanovic@fon.bg.ac.rs
}

\begin{abstract}
A R T I C LE IN F O
A B S T R A C T

Original Article

Received: 20 October 2019

Accepted: 03 February 2020

doi:10.5937/ekoPolj2001037K

UDC 366:634.8(497.11)

Keywords:

Wine, Serbia, preferences, attributes, discrete choice analysis, segmentation

JEL: Q13, C50, C93

The unique and at the same time very complex nature of the wine requires a more thorough selection process compared to other consumer products. Wine consumers are faced with a number of brands, grape varieties, and regions of origin, diverse tastes and prices. Using discrete choice experiment this study explores the importance that consumers in Serbia attach to five attributes of the local wine brands. Respondents were asked to evaluate 10 choice tasks, each with three different wines, and to choose the one that they would like to have with friends or family. The sample results indicate the high importance of the wine brand, while the price proved to be the least important. However, preference-based segmentation identified three clusters that differ primarily in the type of wine they favor, but also whether they like or not sweet and sparkling wines. It turns out that the price is a moderately important attribute in all clusters.
\end{abstract}

(C) 2020 EA. All rights reserved.

\section{Introduction}

Due to the dynamic nature of the wine sector, in recent decades a growing number of practitioners and academics have become interested in analyzing the various stages of the wine consumption process as well as the preferences and behavior of wine consumers. The dynamics are primarily reflected in the diversification of offer, reduced consumption in traditional wine producers and the emergence of new producer and consumer regions (Martinez et al., 2006). Moreover, in developed societies, consumer preferences and behaviour becomes diverse and creates continuous socio-economics changes, but also changes in modern lifestyles. These processes have led to a different pattern of consumption of alcoholic beverages, especially wine, in the sense of reducing

1 Marija Kuzmanović, Ph.D., Associate Professor, University of Belgrade, Faculty of Organizational Sciences, Jove Ilića 154, Belgrade, Serbia, +381 11 3950800, marija. kuzmanovic@fon.bg.ac.rs, ORCID ID (https://orcid.org/0000-0001-5857-6932)

2 Dragana Makajić-Nikolić, Ph.D., Associate Professor, University of Belgrade, Faculty of Organizational Sciences, Jove Ilića 154, Belgrade, Serbia, +381 11 3950800, gis@fon. bg.ac.rs, ORCID ID (https://orcid.org/0000-0002-0790-6791)

http://ea.bg.ac.rs 
the consumption of table wine and increasing demand for quality wines and wines with regional specificity (Caniglia et al., 2006). However, consumers are faced with a choice between non-regional but more familiar wines, and newer, regional or local lesserknown products (Kolyesnikova et al., 2008; Di Vita et al., 2019).

The European Union is the world's leading producer of wine, accounting for about $60 \%$ of global production and consumption, while top producers are Italy, France and Spain (Kotzeva et al., 2018). The wine industry in Republic of Serbia is showing signs of significant growth in last decade. With 198 million tons of wine produced in 2014, Serbia ranked 19th among the world and 12th among European wine producers (FAO, 2015). The majority of Serbian wines are produced in local wineries. A gradual increase in both, production and consumption of high quality wines can be noticed. The growing number of wine producers in Serbia presents a challenge for marketing professionals to formulate a strategy targeting Serbian consumers.

The purpose of this paper is to empirically research the consumers' preferences towards characteristics of local wines in Serbia, as well as to determine whether those preferences are heterogeneous. To our knowledge, several research related to consumers' preferences, wine choice and purchase behaviour were conducted in Serbia (Vlahović et al., 2012; Radovanović et al., 2017). For the purpose of modeling and analyzing consumer preferences in choosing wines, this paper uses the Discrete Choice Analysis (DCA). DCA refers to the class of the probabilistic selection model, which emerged in mathematical psychology. It has been widely used to measure individual preferences in many fields, and in recent years, there has been a growing body of research in wine-related research to address the preferences of both consumers and sellers (Lockshin et al., 2006; Veale \& Quester, 2008; Tempesta et al., 2010; Kallas et al., 2013; Tait et al., 2019).

\section{Related literature}

The unique and at the same time the very complex nature of wine causes a special selection process in comparison with other consumer products. When purchasing, consumers are faced with a huge number of brands, numerous grape varieties and regions of origin, as well as a wide range of prices to choose from (Mueller et al., 2010). Furthermore, the specificity of wine as a product affects the willingness of consumers to even try out a particular type of wine (Everett et al., 2018).

The literature have identified a numerous factors that influence the consumer's wine purchase decision. Two categories of factors are particularly distinguished: extrinsic and intrinsic attributes (MacDonald et al., 2013). Intrinsic attributes are those associated with physical characteristics such as vintage, grape type, year of production and sensory characteristics of the wine such as taste, flavor, sugar content and colour. Extrinsic attributes refer to non-sensory characteristics of wine among which are price, region of origin, brand name and packaging (Lu et al., 2017). 
Although most studies on wine consumer behavior are focused on red (Mehta and Bhanja, 2018; Sena-Esteves et al., 2018) or white wine (Saliba et al., 2009), recent market trends show the growing worldwide popularity of rose wine, leading to an increase in research studies related to this type of wine (Kolyesnikova et al., 2008; Wang \& Jeffery, 2018; Capitello et al., 2019).

The results of numerous studies indicate that wine prices depend on the quality, reputation of the producer and other sensory and non-sensory characteristics of the wine (Lockshin et al., 2006). Therefore, the price can be an important cue when the product cannot be evaluated prior to purchase and when there some risk of making a wrong decision, such as while purchasing wine in the retail stores (Chrea, et al., 2011). Veale and Quester (2008) concluded that respondents perceived even poor quality wines as tasty, if they are expensive and with a reputable country of origin.

In addition to price, grape variety has been found to be one of the most influential factors when buying wine in retail stores (Thomas \& Pickering, 2003; Mehta \& Bhanja, 2018), while region of origin is one of the most important factors for consumers when choosing a wine in restaurants and bars (Corsi et al., 2012). Many authors consider packaging and label design to be major marketing tools for attracting consumers and influencing their choices (Rocchi \& Stefani, 2005; Sáenz-Navajas et al., 2013; Tempesta et al., 2010).

The literature indicate that the region of origin affects consumers' preferences significantly (Kallas et al., 2013). Lecocq and Visser (2006) found out that consumers are willing to pay a higher price for the local and national wines. Perrouty et al. (2006) found that less experienced consumers are more likely to consider wine origins, but some studies showed that even high involved consumers and wine experts can be strongly influenced by this cue. Recently, Escobar et al. (2018) used Generalised Multinomial Logit Model to determine the impact of the 2008 economic crisis on preferences of the citizens of Catalonia towards four wine attributes: wine origin, wine references, grape variety, and price. The research showed that the wine origin was the most important attribute before the crisis, while the price became the most important attribute during the crisis.

\section{Materials and methods}

This study aims to explore the habits and preferences of consumers of wine in Serbia. The results of the study should answer questions such as: (1) Which wine characteristics most influence consumers' choices; (2) How important is price of wine; (3) To what extent consumers' preferences are heterogeneous; (4) Is there a difference between the preferences and behavior of certain socio-demographic groups of respondents; and (5) Whether and to what extent habits arise from or are conditioned by preferences. To determine individuals' preferences, an online discrete choice experiment was conducted on individuals older than 18 years who consumed wine at least once in the past year. 


\section{Discrete choice analysis}

Discrete choice analysis (DCA) is a stated preference method based on micro-economic theory and Lancaster's characteristics approach to consumer demand, according to which consumers attempt to maximize their benefit derived from the consumption of the characteristics of products (products attributes), rather than from products as a whole (Lancaster, 1966; McFadden, 1974).

The basic assumption of the DCA is that any product or service can be defined as a combination of different levels of multiple attributes. In the experimental procedure, individuals are presented with sets of alternatives that differ in the levels of their component attributes, and for each choice set they are asked to choose the most preferred alternative. The outputs from DCA, the so-called utility results, are numerical values that reflect the extent to which each attribute and level influences customer choice (Kuzmanovic et al., 2020).

The benefits of using DCA to reveal the preferences of individuals are numerous. Firstly, the choice tasks are very similar to real purchasing situations in which respondents have to make trade-offs between conflicting attributes such as price and quality. Secondly, DCA preferences are measured indirectly, which can reduce the bias of strategic responses. Furthermore, utilities are calculated at the individual level and can be used for the purpose of post hoc segmentation (Popović et al., 2018).

There are five main steps in conducting Discrete Choice experiments. The first step is to identify the key product attributes and corresponding levels that best describe the product and allow them to differentiate one from the others. An experimental design should be generated based on these attributes and levels. Respondents' answers are then analyzed at the aggregate level using Logit method or for each individual respondent in the sample using Hierarchical Bayes method. In addition to revealing respondents' preferences, the data obtained can be further used for segmentation as well as for predicting and simulating market shares and profits. It is also possible to measure willingness-to-pay for a change in attribute levels.

\section{Attributes used in the experiment}

In accordance with the research objective and based on the literature review, two extrinsic (winery, price) and three intrinsic attributes (type, sweetness and sparkling), were taken into consideration in this study (see Table 1). Depending on grape variety, three types of wine are distinguished. Thus, for an attribute Type we choose three levels: Red, White and Rosé. Wines can be made with a wide range of sweetness levels, from dry to sweet one. According to EU regulation 753/2002 (eur-lex.europa, 2002), the following terms may be used on the labels both table and quality wines depending of the sugar content: Dry, Medium dry, Medium and Sweet. Based on the amount of carbon dioxide in the wine, it can be either sparkling i.e. with significant levels of carbon dioxide in it, making it fizzy, or non-sparkling (still). 
We have developed the levels of the attribute Winery from available data on the Serbian wine market. There is a considerable number of small family winery in Serbia, whose wine is considered to be of high quality and popular among the consumers. Therefore, in addition to an industrial winery with a tradition (Rubin), five more wineries has been taken into account (see Table 1). These wineries were selected for being one of the most popular in Serbia (Portal Vino, 2016). Moreover, in 2016, Cabernet Sauvignon Reserva 2012 "Podrum Radovanović" was declared best Serbian red wine, while Triumph Gold 2015 of Aleksandrović winery was proclaimed as the best white wine. The Best rose wine award went to the Zvonko Bogdan Winery for the popular Rose sec 2015, while the best sweet wine was the Black Tamjanikae 2015 of Matalj Winery. Prices on the Serbian wine market for the wines of these wineries range from 400rsd to 1600rsd, thus the four price points were selected for the attribute Price.

Table 1. Key attributes and corresponding levels

\begin{tabular}{|l|l|l|l|l|l|l|}
\hline Attribute & Level 1 & Level 2 & Level 3 & Level 4 & Level 5 & Level 6 \\
\hline Winery & Rubin & Kovačević & Radovanović & Aleksandrović & Z. Bogdan & Matelj \\
\hline Type & Red & Rose & White & & & \\
\hline Sweetness & Dry & Medium dry & Medium & Sweet & & \\
\hline Sparkling & Sparkling & Non-sparkling & & & & \\
\hline Price & 400 RSD & 800 RSD & 1200 RSD & 1600 RSD & & \\
\hline
\end{tabular}

\section{The choice experiment design and survey technique}

Based on selected attributes and their levels, a total of $576(=6 \times 3 \times 4 \times 2 \times 4)$ virtual wine concepts could be constructed, giving a large number of choice tasks. However, it is unrealistic for respondents to compare and select from such a great number of tasks. Usually respondents are becoming fatigue after comparing more than 15 concepts. Thus, in this study blocked fractional factorial choice design was created using software conjoint.ly. Blocks are partitions of the choice tasks in the design of experiment that contain a limited number of choice questions for each respondent. In our study, an experimental design with 70 choice tasks was partitioned into seven blocks so that each respondent evaluated only 10 choice tasks, each consisted of three full profile wine alternatives plus the "none of the above" option. In this way, the survey covered a total of $210(10 \times 3 \times 7)$ profiles. The no-choice option is included to give a more realistic purchase situation and thus increase data validity. Participants were asked to select the bottle of wine they would most like to buy.

Along with the choice tasks, respondents were presented with a short survey that included socio-demographic data such as age, gender, household income, level of education, as well as data on wine consumption habits (wine type they most commonly drink, drinking frequency, place, and quantity). One of the additional questions was about the willingness to try new wines. To test the questionnaire, the survey was piloted using a sample of 20 respondents. As DCA calculates preferences for each individual respondent, a large sample is not necessary for the results to be valid. To collect responses, this study used an online survey. Online surveys have been shown to be 
suitable for discrete choice experiments due to ease of completion, time savings and high response rates. In accordance with the purpose of the study, the respondents were recruited through convenient sampling method. The survey was distributed on social networks, wine-related forums and distributed by e-mail. The intention was to select participants who would be willing to provide the most relevant information, the request being that they occasionally or frequently consume wine.

\section{Analytical method}

Discrete choice models (DCMs) can be derived from Random utility theory (RUT), providing a mathematical form that associates consumer utilities with product attributes (Zhu, 2007). A DCM specifies the probability that an individual chooses a particular wine concept, with the probability expressed as a function of observed variables that relate to the concepts and the individual. The probability of individual $i$ choosing alternative $j$ from a set of $J$ mutually exclusive alternatives is given by:

$$
P_{i j}=P\left(U_{i j} \geq U_{i k} \mid k \in J\right) \quad \forall k \neq j, i=1, \ldots, I,
$$

where $U_{i j}$ is the utility that individual $i$ obtains from choosing alternative $j$ and can be can be decomposed into an explainable component $V_{i j}$ and random component $e_{i j}$ :

$$
U_{i j}=V_{i j}+\varepsilon_{i j} \text {. }
$$

Random component $e_{i j}$ represents the unobservable or unobserved sources of utility that can be due to unobserved preference variation, variability within and between individuals and measurement error. $V_{i j}$ is a deterministic component of utility associated with the observed factors (attributes) that influence it. The functional form for $V_{i j}$ is usually linear additive form that maps the multidimensional attribute vector into onedimensional total utility:

$$
V_{i j}=\sum_{k=1}^{K} \sum_{l=1}^{L_{k}} \beta_{i k l} x_{j k l} \text {, }
$$

where $\beta_{i k l}$ represents utility respondent $i$ attaches to $l^{\text {th }}$ level of attribute $k, k=1, \ldots, K$ also known as part-worth utility, and $x_{j k l}$ is a binary variable that equals 1 if hostel $j$ contains level $l$ of attribute $k$, otherwise it equals 0 .

To estimate the model parameters (part-worth utilities associated with attribute levels), multinomial logit model or Hierarchical Bayes (HB) estimation can be used. However, in this study HB was used due to its possibility to estimate individual-level parameters. HB estimation implies that hierarchical models are analyzed using Bayesian methods that are based on the assumption that probability is expressed as a degree of belief. The value of the HB model lies in its ability to estimate more parameters with fewer data collected from each respondent. 
Estimated part-worths reflects how strongly that level influences the decision to choose a certain wine. Attributes with large variations in the influence are consider as more important. Accordingly, relative importance of each attribute for each respondent are calculated by dividing the utility range for each attribute separately with the sum of the utility ranges for all attributes (Kuzmanovic et al., 2013):

$$
W_{i k}=\frac{\max _{l} \beta_{i k l}-\min _{l} \beta_{i k l}}{\sum_{k=1}^{K}\left(\max _{l} \beta_{i k l}-\min _{l} \beta_{i k l}\right)} .
$$

These individual values of the relative importance of the attributes can be further used to calculate the attributes importance for the sample as whole if the preferences prove to be homogeneous, or at the cluster level in the case of heterogeneous preferences.

For the purpose of preference-based, i.e. post hoc segmentation, both hierarchical and nonhierarchical clustering techniques can be used. One of the techniques that has proven to be suitable for clustering individual part-worths is k-means cluster analysis. It is a nonhierarchical technique that aims to partition $I$ vectors of part-worths into $k$ clusters in which each observation belongs to the cluster with the closest mean. Despite the fact that the problem of minimizing within-cluster variances is computationally demanding, efficient heuristic algorithms converge quickly to a local optimum. The key feature that make algorithms efficient is that the number of clusters $\mathrm{k}$ is an input parameter. Since inadequate choice of $\mathrm{k}$ may produce poor results, it is important to run diagnostic tests to determine the adequate number of clusters.

\section{Results}

\section{Sample characteristics}

Data were collected online using Conjoint.ly platform in June 2017. In total, 256 individuals answered the survey. After the elimination of incomplete and low quality surveys, an eligible answers of 240 respondents were used in analysis. The sample characteristics as well as respondents' habits concerning wine consumption are presented in Table 2.

As young people use the internet more and are more willing to fill out surveys, it is not surprising that as many as $42.92 \%$ of the sample are students. With regard to the frequency of wine consumption, $34.17 \%$ of respondents indicated they drink wine once a month, $25.83 \%$ drink wine once a week, while only $12.5 \% \%$ of them stated that they drink wine several times a week or even every day $(2.08 \%)$. Respondents state that most often consume wine in restaurants (34.17\%), and most of them drink white wine $(45.42 \%)$. As much as $81.67 \%$ of respondents are willing to try new brands and types of wine, with woman being more willing than men. Only one third of the respondents $(32.5 \%)$ do not choose wine depending on the food they consume, while $31.65 \%$ of them declared that the choice of the wine type is affected by the season. More than half 
of the respondents (60\%) mostly buy domestic (Serbian) wine brands. Furthermore, respondents most often choose to have Rose wine in restaurants or bars (very rarely at home), while red wine they prefer to have at home.

Table 2. Socio-demographics data and respondents' habits

\begin{tabular}{|c|c|c|c|}
\hline Demographic & Category & Frequency & Percentage \\
\hline \multirow[t]{2}{*}{ Gender } & Male & 123 & $51.25 \%$ \\
\hline & Female & 117 & $48.75 \%$ \\
\hline \multirow[t]{4}{*}{ Age } & $18-20$ & 17 & $7.08 \%$ \\
\hline & $21-40$ & 194 & $80.83 \%$ \\
\hline & $41-60$ & 21 & $8.75 \%$ \\
\hline & $>61$ & 8 & $3.33 \%$ \\
\hline \multirow[t]{5}{*}{ Level of education } & Primary school & 9 & $3.75 \%$ \\
\hline & High school & 43 & $17.92 \%$ \\
\hline & Undergraduate & 140 & $58.33 \%$ \\
\hline & Master degree & 45 & $18.75 \%$ \\
\hline & PhD degree & 3 & $1.25 \%$ \\
\hline \multirow[t]{4}{*}{ Employment status } & \begin{tabular}{|l|} 
Student \\
\end{tabular} & 103 & $42.92 \%$ \\
\hline & Unemployed & 16 & $6.67 \%$ \\
\hline & Employed & 116 & $48.34 \%$ \\
\hline & Retired & 5 & $2.09 \%$ \\
\hline \multirow[t]{4}{*}{ Averaged monthly income } & do 25000 & 34 & $14.17 \%$ \\
\hline & $25000-50000$ & 80 & $33.33 \%$ \\
\hline & $50000-75000$ & 58 & $24.17 \%$ \\
\hline & $>75000$ & 68 & $28.33 \%$ \\
\hline \multirow[t]{5}{*}{ Frequency of wine consumption } & Every day & 5 & $2.08 \%$ \\
\hline & Several times a week & 30 & $12.50 \%$ \\
\hline & Once a week & 62 & $25.83 \%$ \\
\hline & Once a month & 82 & $34.17 \%$ \\
\hline & Rarely & 61 & $25.42 \%$ \\
\hline \multirow[t]{4}{*}{ Quantity } & 1 glass & 45 & $18.75 \%$ \\
\hline & 2 glasses & 90 & $37.50 \%$ \\
\hline & 3 glasses & 42 & $17.50 \%$ \\
\hline & at least 4 glasses & 63 & $26.25 \%$ \\
\hline \multirow[t]{4}{*}{ Place of consumption } & At home & 56 & $23.33 \%$ \\
\hline & At friends'/family place & 55 & $22.92 \%$ \\
\hline & In clubs/pubs & 47 & $19.58 \%$ \\
\hline & In restaurant & 82 & $34.17 \%$ \\
\hline \multirow[t]{3}{*}{ Type of wine commonly consumed } & White & 109 & $45.42 \%$ \\
\hline & Red & 66 & $27.50 \%$ \\
\hline & Rose & 65 & $27.08 \%$ \\
\hline
\end{tabular}

Source: Authors' calculations 


\section{Aggregated preferences}

The results of the analysis are given in Figure 1 and Figure 2, with Figure 1 showing the importance of attributes. It can be seen that Winery is the most important attribute to Serbian consumers, with an average importance value of even $59.43 \%$. The attribute Type is shown to be second by importance $(24.69 \%)$. The third ranked attribute is Sweetness (8.8\%) followed by Sparkling (4.92\%), while the least important attribute is Price with importance values of just $2.16 \%$.

Figure 1. Relative importance of attributes (in \%)

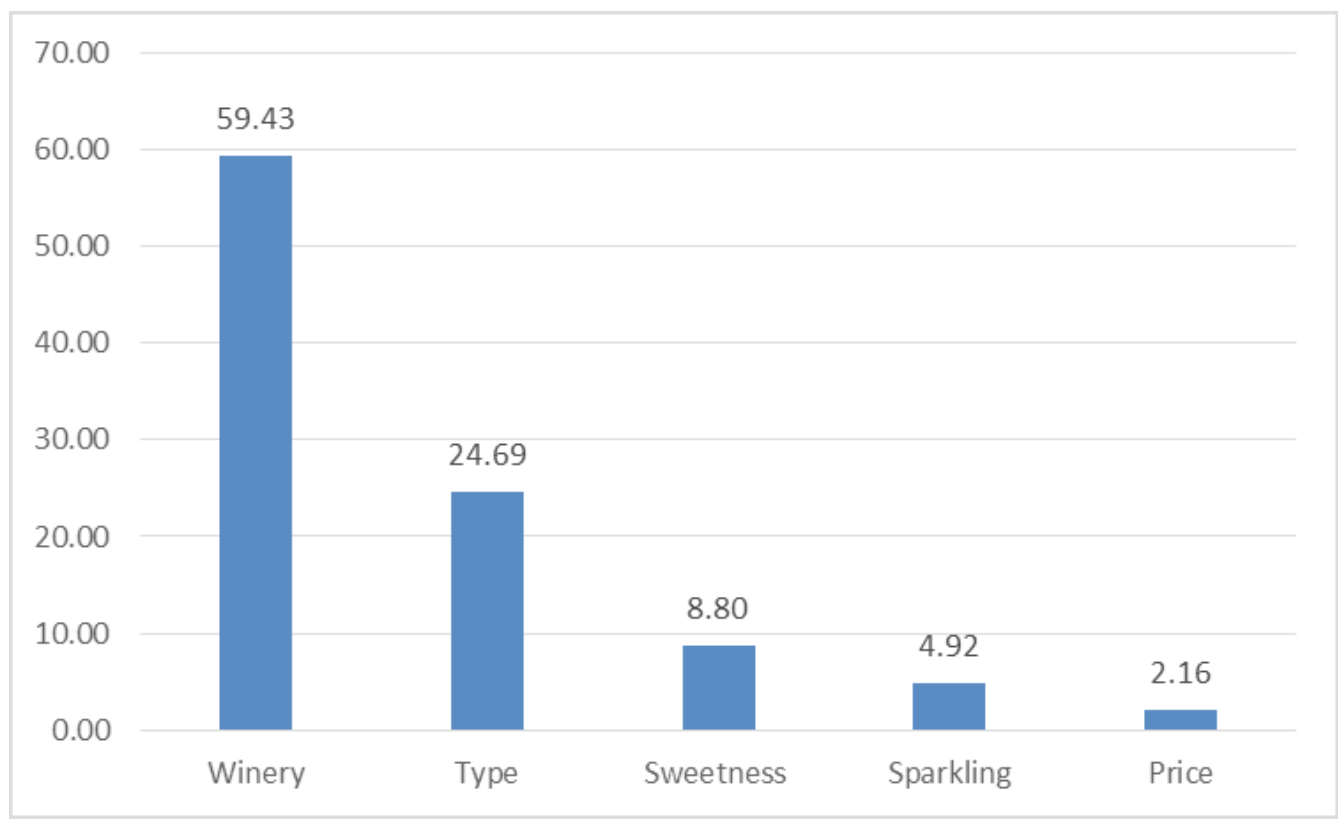

Source: Authors' calculations

A more detailed insight into averaged preferences toward attribute levels (partworths) is given in Figure 2. When it comes to the most significant attribute, Winery, respondents most prefer Kovačević, followed by Radovanović. The least desirable are Matalj and Rubin. On average, respondents almost equally prefer white and rose, and at least red wine, with an affinity for sweeter and sparkling wines. Looking at the price attribute, it can be seen that there is no significant difference between the utilities attached to it levels (price points), with the slightly higher part-worth assigned to the price of $1200 \mathrm{rsd}$. At first glance, respondents do not seem to be price sensitive, which is not in line with findings in the literature where price is one of the most important factors. We further used socio-demographic and psychological variables (gender of the respondents and willingness to try new tastes and wines) to define segments a priori, and to test whether they differ in preferences and behavior. 
Figure 2. Averaged part-worth utilities

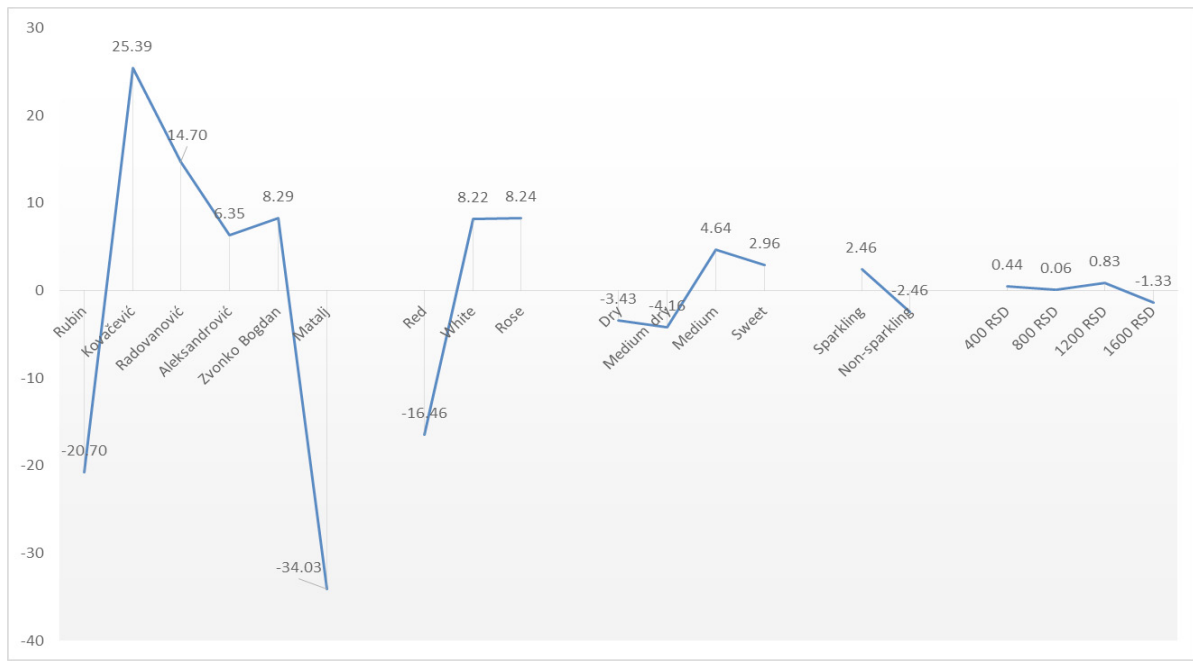

Source: Authors' calculations

As can be seen from Figure 3, there are some differences among the segments when it comes to the importance of attributes. Winery and Price are more significant for men than for women, who in turn, attach more importance to the remaining three attributes. This is especially true for the Type attribute. Furthermore, women prefer sparkling, medium or sweet rosé wines, while men prefer non-sparkling white wines. Those who are unwilling to try new brands and types of wine, attached more importance to the attribute Price and less to the Type attribute than other groups of respondents. They prefer cheap non-sparkling rose wines, unlike the so-called "adventurists" who prefer expensive sparkling white wines.

Figure 3. Segment level part-worth utilities

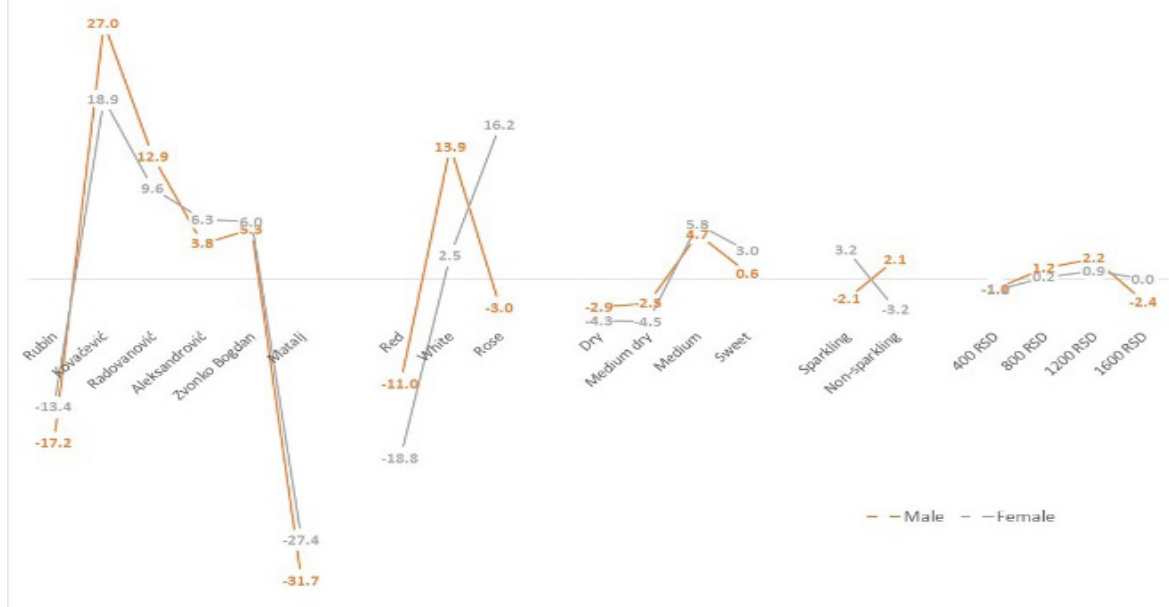



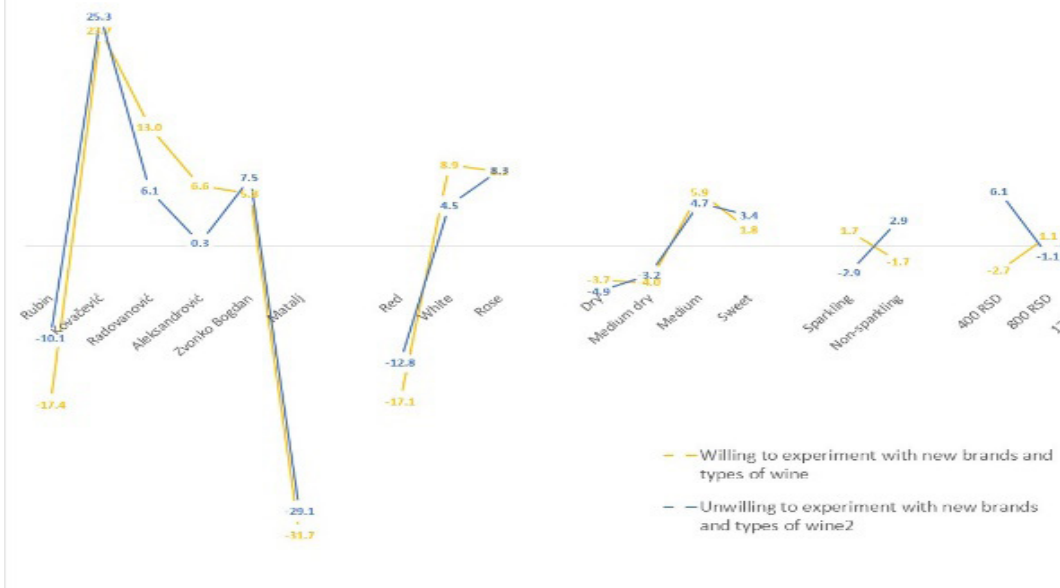

Source: Authors'calculations

\section{Post hoc segmentation}

Aggregated data often blur the real picture of respondents' preferences due to their averaging. The same applies to the preferences of segments defined a priori based on socio-demographic data. This can be overcome by the use of preference-based segmentation procedure. A more detailed analysis of individual part-worth utilities revealed heterogeneity in consumer preferences, so three distinct groups representing authentic market segments were isolated using K-means cluster analysis: dry red wine fans (Cluster 1), sweet rose wine fans (Cluster 2), and expensive white wine fans (Cluster 3). The solution was sought for two, three and four segments, but the threesegment solution proved to be best fit, both in terms of the segments size and sum of squared deviations between part-worth utilities in different segments. Table 3 shows the relative importance of attributes within each segment.

Although price has proven to be the least important attribute throughout the sample, it can be noted that it is significantly more important at the segment level. This result indicates that averaging can cause the loss of important information related to respondents' real preferences, which may be reflected in the wrongly defined market strategy. Similar observations are made for other attributes as well. Once the clusters were identified, socio-demographic data were used to further profile consumers.

Table 3. Relative importance of attributes (in \%)

\begin{tabular}{|l|c|c|c|c|c|}
\hline & Winery & Type & Sweetness & Sparkling & Price \\
\hline Cluster 1 & 33.10 & $\mathbf{3 5 . 1 6}$ & 10.99 & 8.61 & 12.14 \\
\hline Cluster 2 & 22.17 & $\mathbf{3 8 . 2 2}$ & 17.78 & 4.40 & 17.43 \\
\hline Cluster 3 & $\mathbf{3 9 . 5 7}$ & 31.91 & 2.80 & 7.27 & 18.44 \\
\hline
\end{tabular}

Source: Authors' calculations 
The Cluster 1 covers $26.25 \%$ of the respondents and consists mostly of employed male respondents, who regularly consume wine, most often at home. This cluster includes respondents who especially prefer the red wine (which is in sharp contrast with the sample as a whole) and usually consume it (54\%), so it is not surprising that they find the Type to be the most important attribute (35.16\%). Somewhat less important is the attributes of Winery (33.10\%), where respondents prefer Kovačević, Radovanović and Aleksandrović wine brands. The other three attributes are significantly less important to this cluster, even though members prefer non-sparkling dry wines, with the price of up to 800rsd (see Figure 4).

Most of the members of Cluster $1,58.73 \%$ of them, have monthly earnings per household member over 50000 (app. 420 euros), of which 31.75\% exceeds 75000 rsd. $44.45 \%$ of cluster members consume wine at least once a week, usually 2 glasses, most often at home $(31.75 \%)$, and rarely in a club or tavern $(14.29 \%)$.

The second, slightly larger cluster consists of 73 respondents $(30.42 \%)$. The most important attribute for this segment is also Type (importance value $=38.22 \%$ ), but respondents belonging to this cluster prefer rose wine, and to some extent white, at the same time showing considerable aversion towards red wine (see Figure 5). The Winery attribute is much less important for this cluster than for Cluster 1. In the same time, members of the Cluster 2 prefer the Kovačević brand wine by far more than the brands of other wineries. Sweetness and price are approximately equally important attributes (about 17\%), whereby respondents prefer sweeter wines at a price of 400rsd. Cluster members are very price sensitive, with an aversion to the more expensive wines (price of $800 \mathrm{rsd}$ and above), which can be concluded on the basis of the negative part-worths for all price levels except for $400 \mathrm{rsd}$.

Figure 4. Preferences of Cluster 1

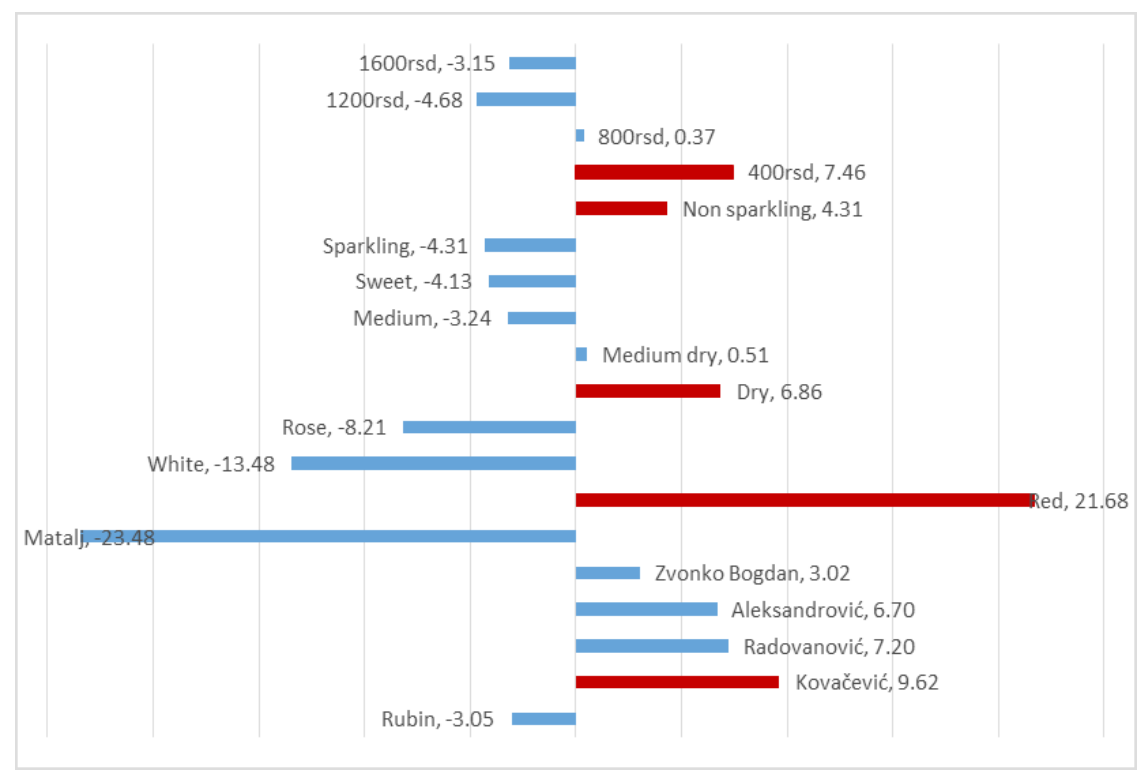

Source: Authors' calculations 
Figure 5. Preferences of Cluster 2

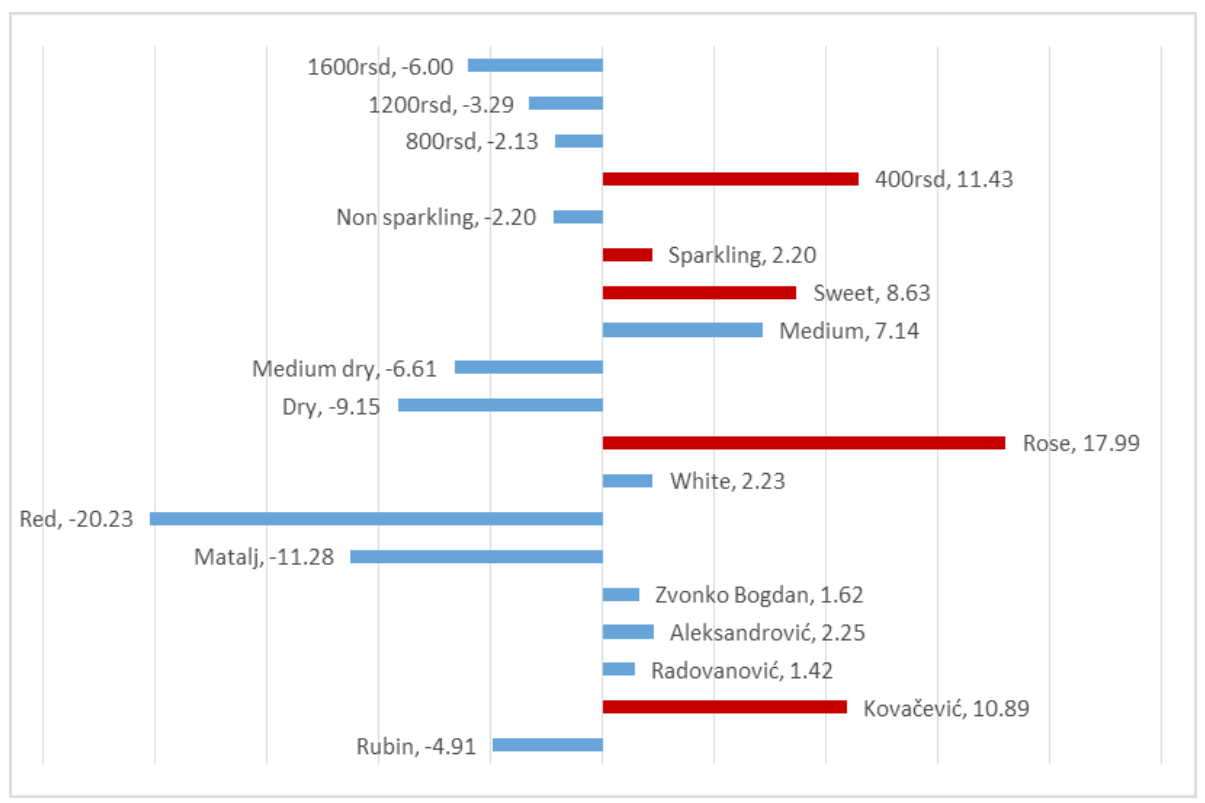

Source: Authors' calculations

The demographic data shows that the majority of the respondents in this segment are young women, with lower earnings and education than the remaining two segments. In fact, as many as $63.2 \%$ of them have incomes lower than RSD 50,000. Members of this segment are least willing to try new flavors and less often consume wine than other clusters. They usually drink rose $(49.32 \%)$ or white wine $(35.62 \%)$, while only $15 \%$ cluster members consume red wine. When it comes to the place of consumption, they prefer a restaurants or a friend's place, rarely drinking in their own home.

Cluster 3 is the largest one (43.33\% of total sample) with Winery as the most important attribute (39.57\%). Members of this cluster prefer Kovačević and Radovanović brands, followed by Zvonko Bogdan. Again, Matalj and Rubin are the least popular wine brands (see Figure 6). The type of wine is the second by importance attribute, whereby the respondents prefer white wine, but have an aversion to red. This cluster is pricesensitive, although the respondents' preferences to price levels are unexpected. In fact, respondents prefer more expensive wines, which can be due to the fact that they use price to conclude about the quality and value of a wine. Moreover, the quality wines of the favourite Serbian producers are exactly in the price range that the members of this cluster prefer. Although sweetness is negligible important attribute for this cluster (only $2.8 \%$ ), respondents prefer semi-sweet (medium) sparkling wines. 


\section{Figure 6. Preferences of Cluster 3}

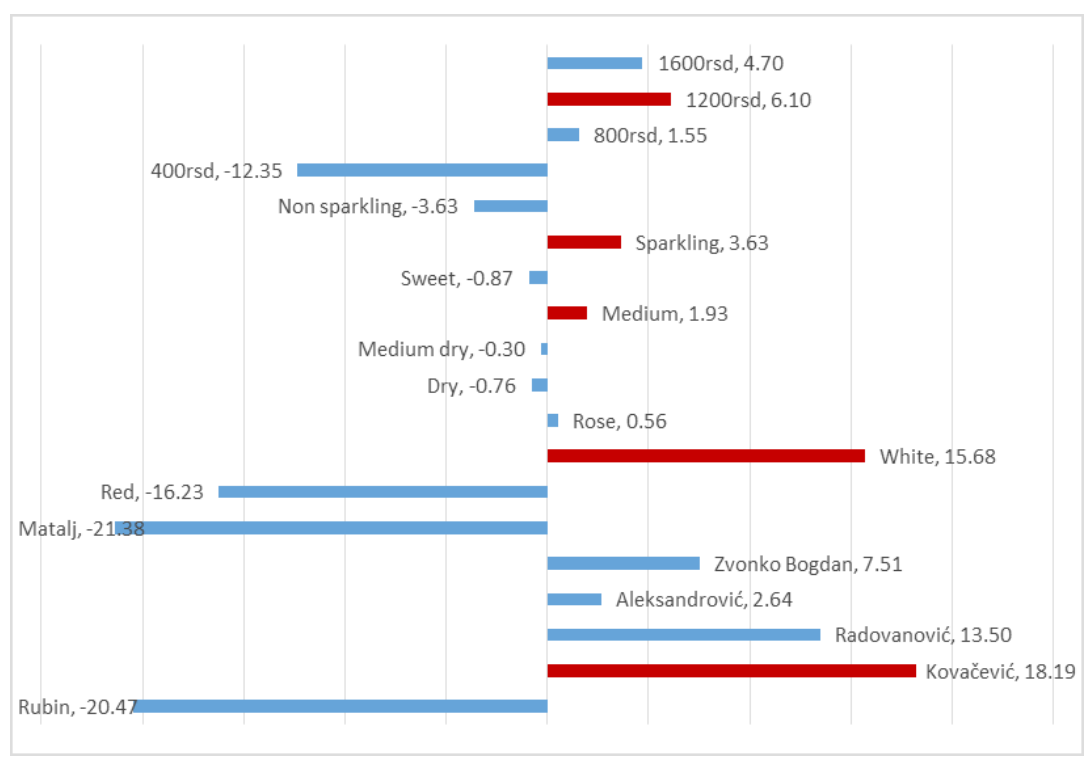

Source: Authors' calculations

Members of cluster 3 have higher incomes than other clusters, with as many as $39.42 \%$ of them earning over 75,000 rsd per household member. Over $40 \%$ of cluster members consume wine at least once a week, with $16.35 \%$ who consume it every day, usually 2 or 3 glasses. As many as $66.35 \%$ of them mainly choose white wine, which is in line with revealed cluster preferences, while only $13.45 \%$ cluster members drink rose wine. They most commonly consume wine in a restaurant $(40.38 \%)$ at home $(31.75 \%)$, and least frequently in clubs or pubs (14.29\%). Of all the clusters, this one is the most willing to try new flavors and wines.

\section{Conclusions}

Due to the large number of different cues that can influence consumers' purchasing decision, the choice of wine is complex task and can be confusing. These cues are typically associated with the physical characteristics of the wine as well as extrinsic attributes such as price and brand, labels and the like. Consequently, understanding how consumers choose wine is a great challenge for both researchers and practitioners.

In this paper, we examined the importance that consumers in Serbia attach to the key attributes of local wine brands. In addition to the brand, four other attributes were considered: price, type of wine, sweetness and whether it is sparking or still. Consumer preferences were modeled using a discrete choice model, while a hierarchical Bayes method was applied to calculate the individual utilities assigned to attribute levels.

The average results of the sample at whole indicated the high importance of brand attributes as well as the negligible importance of price. However, heterogeneity in preferences was 
observed and three unique segments were identified using k-means cluster analysis. These segments differ primarily in the type of wine they favor, but also in whether they like sweet and sparkling wines or not. Price has proven to be a moderately significant attribute in all three clusters, while Kovačević is the preferred brand.

The findings of this study represent the first empirical insights into individual preferences of consumers in Serbia according to wine characteristics using discrete choice analysis. However, since $40 \%$ of the sample drinks wine at most once a week, the question arises as to whether or not the preferences of true wine connoisseurs have been discovered. Future research should be directed towards revealing the preferences of the quality wines connoisseurs.

\section{Conflict of interests}

The authors declare no conflict of interest.

\section{References}

1. Caniglia, E., D’Amico, M., \& Peri, I. (2006). An analysis of consumers' perception of the quality of Doc Etna wine. Proceedings of 3rd International Wine Business \& Marketing Research Conference. Montpellier: France.

2. Capitello, R., Bazzani, C., \& Begalli, D. (2019). Consumer personality, attitudes and preferences in out-of-home contexts: The case of rosé wine in Italy. International Journal of Wine Business Research, 31(1), 48-67, doi: 10.1108/ IJWBR-06-2018-0022

3. Chrea, C., Melo, L., Evans, G., Forde, C., Delahunty, C., \& Cox, D.N. (2011). An investigation using three approaches to understand the influence of extrinsic product cues on consumer behavior: An example of Australian wines. Journal of Sensory Studies, 13(24), 13-24, doi: 10.1111/j.1745-459X.2010.00316.x

4. Corsi, A.M., Mueller, S., \& Lockshin, L. (2012). Let's see what they have... what consumers look for in a restaurant wine list. Cornell Hospitality Quarterly, 53(2), 110-121, doi: $10.1177 / 1938965511428448$

5. Di Vita, G., Caracciolo, F., Brun, F., \& D’Amico, M. (2019). Picking out a wine: Consumer motivation behind different quality wines choice. Wine Economics and Policy, 8(1), 16-27, doi: 10.1016/j.wep.2019.02.002

6. Escobar, C., Kallas, Z., \& Gil, J.M. (2018). Consumers' wine preferences in a changing scenario. British Food Journal, 120(1), 18-32, doi: 10.1108/BFJ-022017-0070

7. eur-lex.europa. (2002). COMMISSION REGULATION (EC) No 753/2002, Retrieved April 2018, from http://eur-lex.europa.eu/LexUriServ/ LexUriServ.do?u ri=CONSLEG:2002R0753:20071214:EN:PDF 
8. Everett, C., Jensen, K., Boyer, C., \& Hughes, D. (2018). Consumers' willingness to pay for local muscadine wine. International Journal of Wine Business Research, 30(1), 58-73, doi: 10.1108/IJWBR-11-2016-0038

9. FAO. (2015). Wine production (tons). Food and Agriculture Organization of the UN. Retrieved January 2019, from http://www.fao.org/faostat/en/\#data/QD

10. Kallas, Z., Escobar, C., \& Gil, J. (2013). Analysis of consumers' preferences for a special-occasion red wine: Adual response choice experiment approach. Food Qualityand Preference, 30(2), 156-168, doi: 10.1016/j.foodqual.2013.05.008

11. Kolyesnikova, N., Dodd, T., \& Duhan, D. (2008). Consumer attitudes towards local wines in an emerging region: a segmentation approach. International Journal of Wine Business Research, 20(4), 321-334, doi: 10.1108/17511060810919434

12. Kotzeva, M., Brandmüller, T., Önnerfors, A., \& Reinecke, P. (2018). Eurostat regional yearbook. Luxembourg: Publications Office of the European Union, doi: $10.2785 / 231975$

13. Kuzmanovic, M., Radosavljevic, M., \& Vujosevic, M. (2013). Understanding student preferences for postpaid mobile services using conjoint analysis. Acta Polytechnica Hungarica, 10(1), 159-176, doi: 10.12700/APH.10.01.2013.1.9.

14. Kuzmanovic, M., Makajic-Nikolic, D., \& Nikolic, N. (2020). Preference Based Portfolio for Private Investors: Discrete Choice Analysis Approach. Mathematics, 8(1), 30, doi: 10.3390/math8010030

15. Lancaster, K. (1966). A new approach to consumer theory. Journal of Political Economy, 74(2), 132-157.

16. Lecocq, S., \& Visser, M. (2006). What determines wineprices: objective vs. sensory characteristics. Journal of Wine Economics, 1(1), 42-56, doi: 10.1017/ $\underline{\mathrm{S} 1931436100000080}$

17. Lockshin, L., Jarvis, W., d'Hauteville, F., \& Perrouty, J.P. (2006). Using simulations from discrete choice experiments to measure consumer sensitivity to brand, region, price, and awards in wine choice. Food quality and preference, 17(3-4), 166-178, doi: $10.1016 /$ j.foodqual.2005.03.009

18. Lu, L., Rahman, I., \& Chi, C. (2017). Ready to Embrace Genetically Modified Wines? The Role of Knowledge Exposure and Intrinsic Wine Attributes. Cornell Hospitality Quarterly, 58(1), 23-38, doi: 10.1177/1938965516629775

19. MacDonald, J., Saliba, A., \& Bruwer, J. (2013). Wine choice and drivers of consumption explored in relation to generational cohorts and methodology. Journal of Retailing and Consumer Services, 20(3), 349-357, doi: 10.1016/j. jretconser.2013.01.013

20. Martinez, L. M., Mollá-Bauzá, M.B., Gomis, F. J., \& Poveda, Á.M. (2006). Influence of purchase place and consumption frequency over quality wine preferences. Food Quality and Preference, 17(5), 315-327, doi: 10.1016/j.foodqual.2005.02.002 
21. McFadden, D. (1974). Conditional logit analysis of quali-tative choice behavior. In Z. P., Frontiers in econometrics (pp. 105-142). New York: Academic Press.

22. Mehta, R., \& Bhanja, N. (2018). Consumer preferences for wine attributes in an emerging market. International Journal of Retail \& Distribution Management, 46(1), 34-48, doi: 10.1108/IJRDM-04-2017-0073

23. Mueller, S., Lockshin, L., Saltman, Y., \& Blanford, J. (2010). Message on a bottle: The relative influence of wine back label information on wine choice. Food Quality and Preference, 21(1), 22-32, doi: 10.1016/j.foodqual.2009.07.004

24. Perrouty, J., d'Hauteville, F., \& Lockshin, L. (2006). The influence of wine attributes on region of origin equity: An analysis of the moderating effect of consumer's perceived expertise. Agribusiness: An International Journal, 22(3), 323-341, doi: 10.1002/agr.20089

25. Portal Vino. (2016, December 16). Retrieved from vino.rs: https:/www.vino.rs/ aktuelno/u-fokusu/item/2101-best-of-2016-godina-sumadijskih-trijumfa.html

26. Popovic, M., Kuzmanović, M., \& Savić, G. (2018). A comparative empirical study of Analytic Hierarchy Process and Conjoint analysis: Literature review. Decision Making: Applications in Management and Engineering, 1(2), 153-163, doi: $\underline{10.31181 / \mathrm{dmame} 1802160 \mathrm{p}}$

27. Profeta, A., \& Hamm, U. (2019). Do consumers prefer local animal products produced with local feed? Results from a Discrete-Choice experiment. Food Quality and Preference(71), 217-227, doi: 10.1016/j.foodqual.2018.07.007

28. Radovanović, V., Đorđević, D. Ž., \& Petrović, J. (2017). Wine Marketing: Impact of Demographic Factors of Serbian Consumers On the Choice of Wine. Economic Themes, 55(2), 199-215, doi: 10.1515/ethemes-2017-0012

29. Rocchi, B., \& Stefani, G. (2005). Consumers' perception of wine packaging: A case study. International Journal of Wine Marketing, 18, 33-44, doi: $\underline{10.1108 / 09547540610657669}$

30. Sáenz-Navajas, M., Campo, E., Sutan, A., Ballester, J., \& Valentin, D. (2013). Perception of wine quality according to extrinsic cues: The case of Burgundy wine consumers. Food Quality and Preference, 27, 44-53, doi: 10.1016/j. foodqual.2012.06.006

31. Saliba, A. J., Wragg, K., \& Richardson, P. (2009). Sweet taste preference and personality traits using a white wine. Food Quality and Preference, 20(8), 572-575, doi: 10.1016/j.foodqual.2009.05.009

32. Sena-Esteves, M., Mota, M., \& Malfeito-Ferreira, M. (2018). Patterns of sweetness preference in red wine according to consumer characterization. Food Research International, 106(4), 38-44, doi: 10.1016/j.foodres.2017.12.043 
33. Tait, P., Saunders, C., Dalziel, P., Rutherford, P., Driver, T., \& Guenther, M. (2019). Estimating wine consumer preferences for sustainability attributes: A discrete choice experiment of Californian Sauvignon blanc purchasers. Journal of Cleaner Production, 233, 412-420, doi: 10.1016/j.jclepro.2019.06.076

34. Tempesta, T., Giancristofaro, R. A., Corain, L., Salmaso, L., Tomasi, D., \& Boatto, V. (2010). The importance of landscape in wine quality perception: An integrated approach using choice-based conjoint analysis and combination-based permutation tests. Food Quality and Preference, 21(7), 827-836, doi: 10.1016/j. foodqual.2010.04.007

35. Thomas, A., \& Pickering, G. (2003). The importance of wine label information. International Journal of Wine Marketing, 15(2), 58-74, doi: 10.1108/eb008757

36. Veale, R., \& Quester, P. (2008). Consumer sensory evaluations of wine quality: The respective influence of price and country of origin. Journal of Wine Economics, 3(1), 10-29, doi: $10.1017 /$ S1931436100000535

37. Vlahović, B., Potrebić, V., \& Jeločnik, M. (2012). Preferences of wine consumers on Serbian market. Economics of Agriculture, 59(1), 37-49, DOI: 10.22004/ ag.econ. 123957

38. Wang, J., \& Jeffery, D. (2018). Rose and China: Aroma and sensory profiles of Australian rose wines and their likely impression in the Chinese market. Wine \& Viticulture Journal, 33(2), 62.

39. Zhu, Q. (2007). Consumer preferences for internet services: A Choice-Based conjoint study. University of Georgia. 